\title{
BEHAVIOR OF CIRCULAR TUNNELS CROSSING ACTIVE FAULTS
}

\author{
Mahsa GHARIZADE VARNUSFADERANI, Aliakbar GOLSHANI * and Reza NEMATI
}

\author{
Faculty of Civil and Environmental Engineering, Tarbiat Modares University, Tehran, Iran
}

*Corresponding author's e-mail: golshani@modares.ac.ir

\section{ARTICLE INFO}

Article history:

Received 1 December 2014

Accepted 8 July 2015

Available online 11 September 2015

Keywords:

Finite elements

Earthquake magnitude

Fault displacement

Normal fault

Reverse fault

Fault dip angle

Tunnel lining deformation

\begin{abstract}
A review of seismic damages suffered by underground structures shows that most tunnels were located near active faults. In a near field seismic event, the rupture of an earthquake fault generates large ground displacements referred to "fling step" effects. The present study investigates the response of tunnel to static fault displacement according to different earthquake magnitudes by using a 2D finite elements program.

The results indicate that the fault mechanism, tunnel position, amount of slip, and earthquake magnitude have significant effects on tunnel lining response, making considerable changes in sectional forces, displacement, and shear distortion on tunnel lining. Reverse faults have more effects on sectional forces of lining comparing to normal faults. The displacement of the lining section under reverse faults is greater than the one under normal faults, except for earthquake magnitudes greater than Ms 7. The shear distortion of the lining section under normal faults located in hanging wall side (i.e. moving bottom boundary of faulting) is higher than the one in footwall side (i.e. fixed bottom boundary of faulting). This is opposite for reverse faults. Finally, in normal mechanism, the recommended safe distance from fault tip is smaller than that of reverse mechanism.
\end{abstract}

\section{INTRODUCTION}

Historically, underground structures are considered to be less vulnerable to seismic excitations compared to structures built on the surface. However, the associated risk may be high, since even a low level of damage may affect their serviceability, like what happened in recent earthquakes recorded in 1995 Kobe (Japan), 1999 Chi-Chi (Taiwan) and 2004 Niigata (Japan) (Corigliano, 2007). Based on Dowding and Rozen's study (1978), underground structures damages could be categorized into three main groups, with regard to the earthquake:

1. Damage from ground shaking

2. Damage from fault dislocation

3. Damage by earthquake-induced ground failures (e.g. liquefaction and landslides).

To the authors' best knowledge, seismic damages on underground structures happen when tunnels are built in the vicinity of causative faults (Corigliano, 2007). The characteristics of near-field ground motion can be significantly different from those of the far-field ground motions. The ground motion close to an active fault may be characterized by strong pulses (Corigliano, 2007). There are many factors which can severely affect ground motion. For instance, the rupture mechanism, the direction of rupture propagation relative to the site, as well as possible permanent ground displacements due to fault slip, are mentioned as the most important factors (Corigliano, 2007).
A literature review shows that there is no recommendation or specification for underground structures designing, influenced by fault movement. As a result, some researchers endeavored to study this issue using numerical analysis and experimental methods. To mention a couple, Lin et al. (2007), established a full-scale numerical model for tunnels, based on a calibrated small-scale model, in line with the model experiments. They studied the effects of thrust faulting at an angle of on $60^{\circ}$ a cylindrical tunnel section for different soil parameters and the tunnel positions toward fault rupture (Lin et al., 2007). They found that the existence of the tunnel and its location influence on the development of a shear zone in the soil. A fault zone developed by thrust fault will induce the failure of the lining, especially for tunnels located inside the shear zone. Furthermore, the soil stress and load in the lining will also be significantly affected by the potential occurrence of a back-thrust shear zone. Based on their study, the soil properties, especially the stiffness, affect the development of shear zones, back-thrust, and the safety of the lining as well. Anastasopoulos and Gazetas (2010) studied the effects of normal fault rupture on cut-and-cover tunnels. They found that, in all cases investigated, the rupture path is severely affected by existence of the tunnel. Due to the developing interaction between the tunnel and the rupture, the imposed deformation of faulting is converted to a diffuse differential displacement acting at the base of the tunnel. Depending on the position of the tunnel with respect 
to the emerging fault rupture, the structure may be subjected either to hogging deformation or to sagging deformation. Moreover, they found that the overburden soil has dual role, so that, it pushes the tunnel to compress the soil underneath; and also, it increases the confining stresses underneath the tunnel, thus it facilitates the bifurcation of fault zone. Generally, soil compliance is beneficial for the distress of the tunnel during fault rupture, but not necessarily for its rotation.

This paper aims to develop a model by using nonlinear finite elements method (FEM) in order to evaluate deformations and sectional forces in tunnel lining, under permanent displacement due to fault slip. The safe distance from the fault tip is then, determined, depending on fault type. The dip slip mechanisms are shown in. As illustrated in Figure 1, depending on fault type, hanging wall side moves up or down relative to footwall side. The hanging wall and footwall sides are moving and fixed bottom boundary of faulting, respectively.
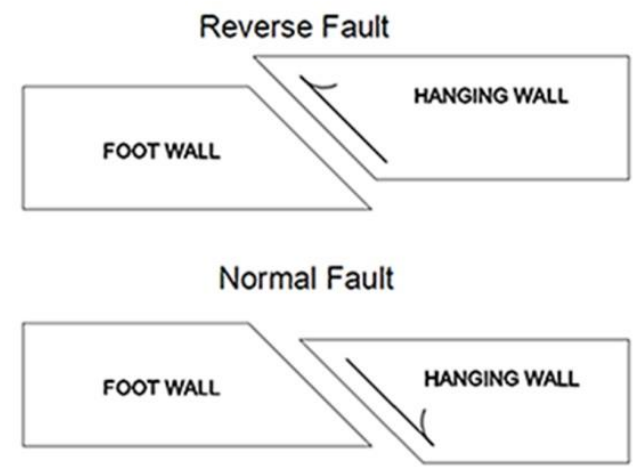

Fig. 1 Schematic mechanisms of dip-slip fault types.

\section{METHODOLOGY}

\subsection{STEPS OF ANALYSIS}

In this research, a finite-elements method (FEM) was adopted for the numerical analysis which was carried out in three steps:

- In "step 1", the in-situ geostatic stresses were modeled and the coefficient of lateral soil pressure was assumed to be $K_{0}=1-\sin \varphi$ (Jaky, 1944).

- In "step 2", when the equilibrium of in-situ geostatic stresses reached, the soil in the tunnel section was removed with a relaxation factor of 40 percent, and the segmental tunnel lining was then installed. Removing the tunnel section and installing simultaneously the tunnel lining, lead to supporting forces that are $50 \%$ to $100 \%$ overestimated (Einstein and Schwartz, 1979). The possibility of occurrence of deformations around the tunnel leads to reducing the support forces, which are more realistic. In this study, in order to simulate real excavation considering 3D modeling effects, results of a two and threedimensional tunnel excavation models were compared, based on a finite elements method. Accordingly, some parameters like tunnel vault and invert deformations (i.e. the measure of convergence at the tunnel section) were measured in 3D tunnel excavation model. These deformations were then created in 2D tunnel excavation model by considering are laxation factor applied to the soil stresses around the tunnel opening. Finally, by comparing these models, it is revealed that a relaxation factor of 40 percent is required for $2 \mathrm{D}$ tunnel excavation model.

- Finally in "step 3", the fault slip was applied by changing boundary conditions and making displacement in hanging wall side, depending on type of fault (normal or reverse fault). In fact, both the fixed boundary condition at bottom and rolling condition at the side of the hanging wall were changed to moving boundary conditions (composed of horizontal and vertical displacement) with the assumed dip angle for fault (Fig. 1). The type of fault determines the directions of moving. By the normal fault slip, the hanging wall moves right and downward. While, it moves inversely, by the reverse fault slip.

\subsection{MODEL PROPERTIES}

The numerical model was set to have a long length, so as to reduce the effect of boundary conditions on the obtained results. Following the recommendations of Bray (1990), Bray et al. (1994), total length of the finite elements model should be at least $4 \mathrm{H}(\mathrm{H}$ is the thickness of soil deposit). In addition, this long length helps to consider probable distances between the fault tip line and the tunnel. The tunnel's full-scale model corresponds to an actual shield tunnel in the Taipei metro system. This tunnel runs close to the Taipei fault with varied distance (Lin et al., 2007; Chung et al., 2005). The model dimensions are shown in Table 1. The configuration of the tunnel, fault rupture, boundary conditions, and fault dip angle adopted for numerical study are shown in Figure 2. Not having complete information about

Table 1 Summary of the model dimensions (Lin et al., 2007).

\begin{tabular}{ccc}
\hline Parameters & dimensions & Unit \\
\hline$L$ & 120 & $m$ \\
$H$ & 20 & $m$ \\
$T$ & 11 & $m$ \\
$D$ & 6.1 & $m$ \\
$\dot{L}$ & 40 & $m$ \\
\hline
\end{tabular}

Remark:

L: length of numerical model; H: depth of soil; T: tunnel depth;

D: Tunnel diameter; L': length of hanging wall 


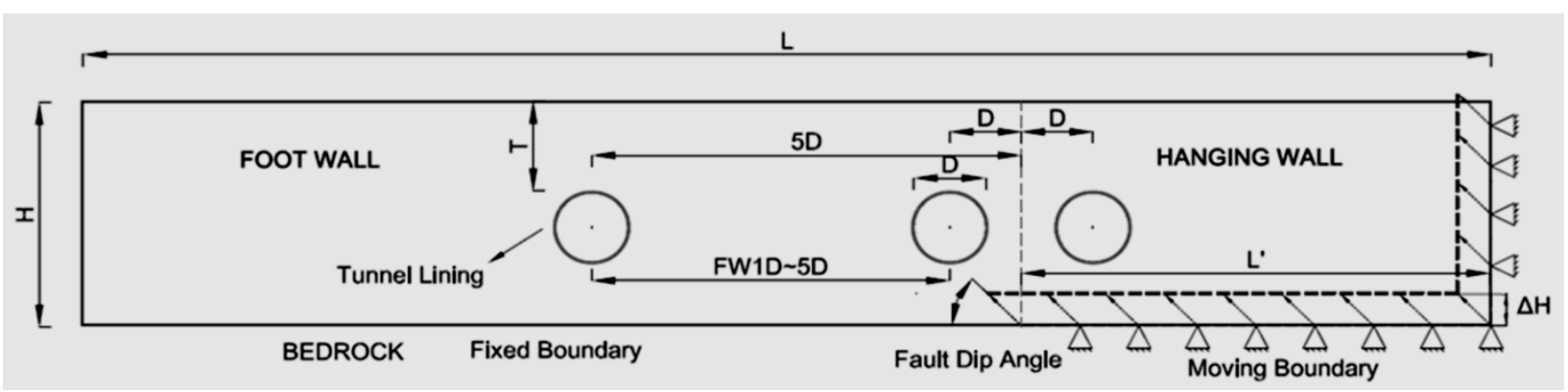

Fig. 2 Illustration of the tunnel configuration, fault rupture, boundary conditions and fault dip angle adopted for numerical study (Lin et al., 2007).

accurate distance of fault line to the tunnel axis, it is reasonable to study this structure at different locations relative to assumed fault tip line. As shown in this Figure, a roller condition is assigned for left and right sides of the model, before faulting. Simulating the fault movement, the fixed boundary condition at right side (hanging wall side) was changed to moving up and downward condition.

The hypothetical shield tunnel had an outer radius of $3.05 \mathrm{~m}$ and a thickness of $0.25 \mathrm{~m}$ (Lin et al., 2007). Basically, the assembly of concrete lining in engineering practice is formed of segments and joints. In this model, the segments of lining were modeled by continuous ring of beam element along with considering a discounted rigidity of lining at joints (Muir Wood, 1975; Lee et al., 2001; ITA, 2000). As described in Lin et al. (2007), the hypothetical shield tunnel included twelve segments and joints. Considering the discounted rigidity of the tunnel lining at the joints, the beam cross sectional area was reduced by half (Lin et al., 2007). The segments and joint sections were $1,0.5 \mathrm{~m}$ long, respectively and $0.25 \mathrm{~m}$ wide (see Figure 3). Table 2 presents a summary of soil and structural parameters. As given in Table 2 two categories of soil parameters were used

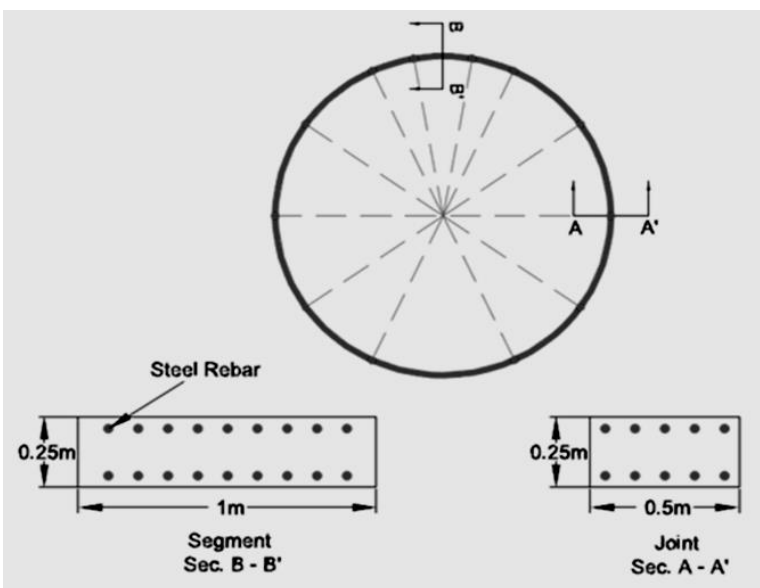

Fig. 3 Typical setup of the segmental lining. A complete circular ring is formed by 12 segments and joints (a) cross section B-B' without joint. (b) equivalent cross section at joint A-A' (Lin et al., 2007).
Table 2 Summary of the material properties considered in this study (Lin et al., 2007).

\begin{tabular}{|c|c|c|c|}
\hline \multicolumn{3}{|c|}{ Parameters } & Unit \\
\hline \multirow{2}{*}{ Tunnel model } & $E_{s}$ & 31800 & $M P a$ \\
\hline & $v_{s}$ & 0.2 & - \\
\hline \multirow{6}{*}{ Soil model } & $\gamma$ & 20 & $\mathrm{kN} / \mathrm{m}^{3}$ \\
\hline & $E$ & 19 & $M P a$ \\
\hline & $v$ & 0.3 & - \\
\hline & $c$ & 5 & $k P a$ \\
\hline & $\varphi$ & 30 & - \\
\hline & $\psi$ & 30.6 & - \\
\hline \multicolumn{4}{|l|}{ Remark } \\
\hline \multicolumn{4}{|c|}{$\begin{array}{l}\text { E: Elasticity modules; } v_{s}: \text { Poisson ratio; } \gamma: \text { Specific density, } \\
c: \text { Cohesion; } \varphi: \text { Friction angle; } \psi: \text { Dilation angle. }\end{array}$} \\
\hline
\end{tabular}

for the analysis. The first one with dilation angle of 30 was used for verification process, and the second one with dilation angle of 6 was used for the main analysis and results.

Overall, the following prerequisites are assumed for the present model:

- The utilized mechanical properties of material (like cohesion, friction, and modulus of elasticity) were suggested by Lin et al. (2007). They obtained these parameters from site investigations.

- An elasto-plastic constitutive model, with MohrCoulomb failure criterion and a linear elastic behavior were adopted for soil material and tunnel lining, respectively (see section 2-3).

- The ground mass was modeled under the condition of two- dimensional plane strain using quadrilateral linear elements with the capability of re-meshing the model. This capability helps not to have excessive distortion in elements during large deformation.

- The tunnel lining was modeled as an elastic beam element.

- Concerning the soil-tunnel lining interaction, a tangential behavior with friction coefficient of $0.36(\mu=\tan (2 \varphi / 3))$ and a normal behavior with 
allowable nodal separation was adopted for soillining interface (Lin et al., 2007).

\subsection{CONSTITUTIVE MODEL}

As mentioned in last section, an elasto- plastic constitutive model without isotropic strain softening was considered for soil behavior. Moreover, based on physical and numerical modeling studies, it is found that this model can make a good connection between their results. Lin et al. (2007) utilized the finite element method and an elasto-plastic constitutive soil model with Mohr- Coulomb failure criterion. They established a full scale numerical model based on a calibrated small scale one. In fact, input parameters, boundary conditions and other factors in small scale numerical model were modified until its results met well with the experimental results. Furthermore, Loukidis et al. (2009) assigned an elasto-plastic model with Mohr-Coulomb yield surface in case of loose sand, without strain softening. It is noteworthy to mention that the granular soil type was in the same group for all these studies. In fact, the soil type (loose or dense) dominates its behavior. In case of loose sand, it does not indicate softening as it is shearing. In this study, used soil parameters are categorized into loose sand group; in line with the paper published by Lin et al. (2007), and accordingly, this constitutive model is appropriate to show the shearing behavior of soil.

\subsection{PERMANENT FAULT DISPLACEMENTS}

Fault displacement is the rupture characteristic which can be estimated by geologic studies of active faults. In fact, it is found that the earthquake magnitude can be correlated with these source characteristics. Accordingly, it is required to develop some relations between rupture parameters and measure of earthquake size, typically magnitude (Wells and Coppersmith, 1994). In this way, numerous published empirical relationships relate earthquake magnitude to various fault rupture parameters (Tocher, 1958; Iida, 1969; Albee and Smith, 1966; Chinnery, 1969; Ohnaka, 1978; Slemmons, 1977, 1982; Acharya, 1979; Bonilla and Buchanon, 1970; Bonilla et al., 1984; Slemmons et al., 1989; Wells and Coppersmith, 1994). In this study, the latest and revised empirical relationships based on Wells and Coppersmith's study were chosen to prescribe average fault displacement. They collected a data base of source parameters for 421 historical earthquakes, publishing new empirical relationships in relation to earthquake magnitudes to surface rupture length, subsurface rupture length, maximum rupture area, and average fault displacement (Well sand Coppersmith, 1994). Based on their study from 56 earthquakes, the average displacement of reverse and normal faults is correlated with earthquake magnitudes of 5.8 to 7.4 and 6 to 7.3, respectively. In this study, the average fault displacements were obtained, using these relationships
Table 3 Average permanent displacement (Wells and Coppersmith, 1994).

\begin{tabular}{|c|c|c|c|c|c|}
\hline \multirow{2}{*}{$\begin{array}{l}\text { Fault } \\
\text { type }\end{array}$} & \multirow{2}{*}{$\begin{array}{c}\text { Dip } \\
\text { angle }\end{array}$} & \multirow{2}{*}{$\begin{array}{l}\text { comp } \\
\text { onent }\end{array}$} & \multicolumn{3}{|c|}{ Average displacement (m) } \\
\hline & & & $\mathrm{M}_{\mathrm{w}}(6)$ & $\mathrm{M}_{\mathrm{w}}(6.5)$ & $\mathrm{M}_{\mathrm{w}}(7)$ \\
\hline \multirow{7}{*}{$\mathrm{R}$} & \multicolumn{2}{|c|}{ Total slip } & 0.55 & 0.603 & 0.661 \\
\hline & \multirow{2}{*}{45} & $\mathrm{H}$ & 0.389 & 0.426 & 0.476 \\
\hline & & V & 0.389 & 0.426 & 0.476 \\
\hline & \multirow{2}{*}{60} & $\mathrm{H}$ & 0.275 & 0.302 & 0.331 \\
\hline & & $\mathrm{V}$ & 0.476 & 0.522 & 0.572 \\
\hline & \multirow{2}{*}{75} & $\mathrm{H}$ & 0.142 & 0.156 & 0.171 \\
\hline & & $\mathrm{V}$ & 0.531 & 0.582 & 0.638 \\
\hline \multirow{7}{*}{$\mathrm{N}$} & \multicolumn{2}{|c|}{ Total slip (m) } & 0.214 & 0.442 & 0.912 \\
\hline & \multirow{2}{*}{45} & $\mathrm{H}$ & 0.151 & 0.313 & 0.645 \\
\hline & & V & 0.151 & 0.313 & 0.645 \\
\hline & \multirow{2}{*}{60} & $\mathrm{H}$ & 0.107 & 0.221 & 0.456 \\
\hline & & $\mathrm{V}$ & 0.185 & 0.383 & 0.790 \\
\hline & \multirow{2}{*}{75} & $\mathrm{H}$ & 0.055 & 0.114 & 0.236 \\
\hline & & $\mathrm{V}$ & 0.207 & 0.427 & 0.881 \\
\hline \multicolumn{6}{|c|}{$\begin{array}{l}\text { Remark } \\
N: \text { Normal fault type; } R: \text { Rev } \\
M_{w}: \text { Earthquake magnitude; } \\
\text { H: Horizontal component of } \\
\text { V: Vertical component of fau } \\
\text { Dip angel is in degree and re }\end{array}$} \\
\hline
\end{tabular}

for earthquakes with magnitudes of $6,6.5$, and 7 (Table 3).

\subsection{VERIFICATION OF THEFULL-SCALE NUMERICAL MODEL}

Based on a full-scale numerical model developed by Lin et al. (2007), modeling method validated through qualitative (zone of plastic shear strain) and quantitative (P-M curve for tunnel lining) comparisons. This model evaluates the thrust fault propagation at the dip angle of $60^{\circ}$ with a vertical displacement of $\Delta H / H=0.08 \quad(\Delta H \quad$ is vertical displacement, and $H$ is the depth of soil) and its impact on a circular tunnel located at FWID (FW denotes footwall, $D$ is tunnel diameter and $1 D$ denotes the horizontal distance equal to the tunnel diameter (1D) between lining center and fault tip line in bedrock). The model configuration is the same as described in Figure 2. The thrust fault slip was simulated by upward moving of the hanging wall side. In Figure 4, the $P-M$ curve (axial load capacity versus moment capacity) obtained for the lining in the established numerical model, corresponds to the one obtained by Lin et al. (2007). As shown in this Figure, the axial force and the bending moment of the lining section, range between 100 to $2000 \mathrm{kN}$, and zero to $1800 \mathrm{kN} . \mathrm{m}$, respectively. Figure 5 shows the zone of plastic shear strain concentration. Location of the plastic shear strain concentration and measure of the strains in the established numerical model are sporoximately in complete agreement with the one obtained by Lin et al. (2007). According to the plastic shear zone, the rupture path bifurcation occurred, as it met the tunnel, and continued to the surface. The tunnel was confined with the propagated shear zone. This caused to load on the tunnel lining and displace it. 
(a)

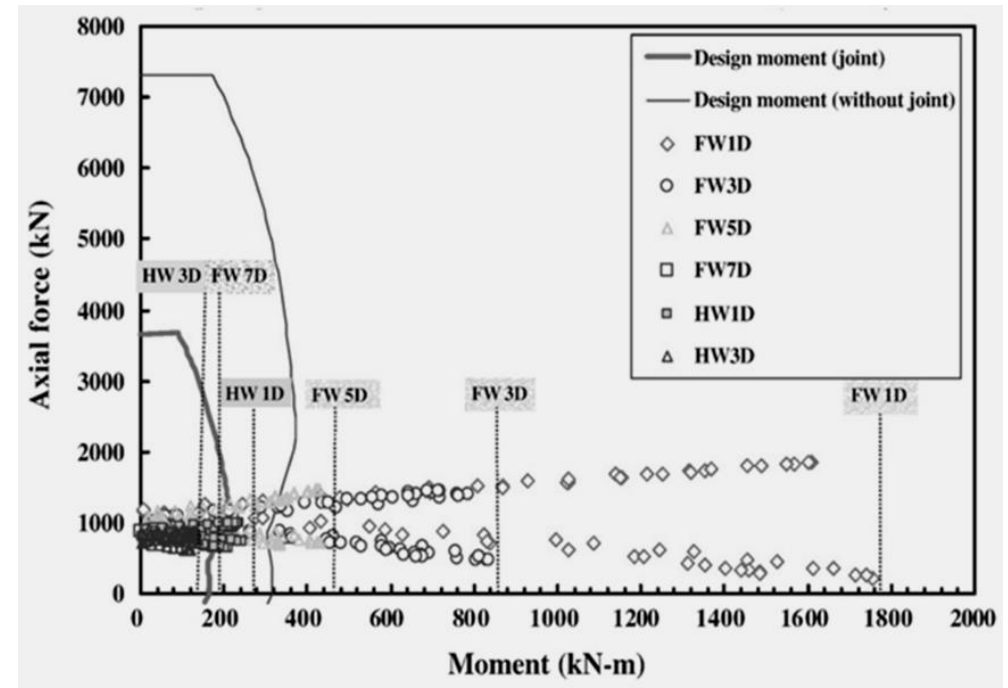

(b)

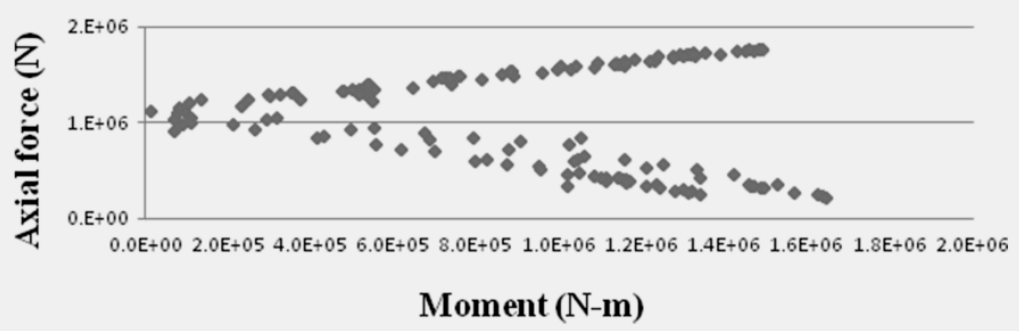

Fig. 5 The P-M curves of the lining as well as the load state, obtained by the established numerical model.

(a)
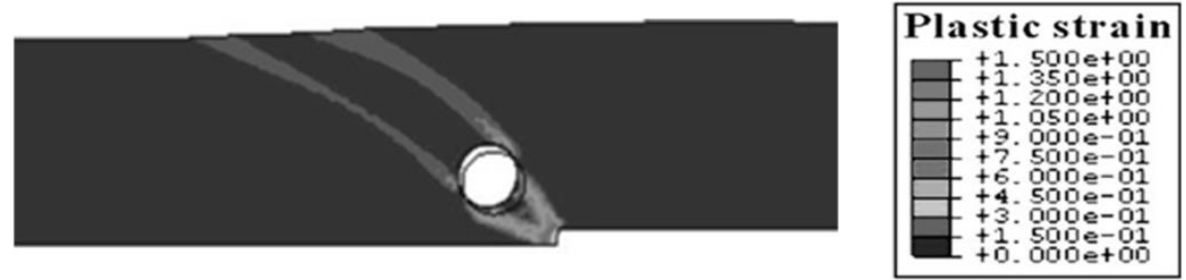

(b)
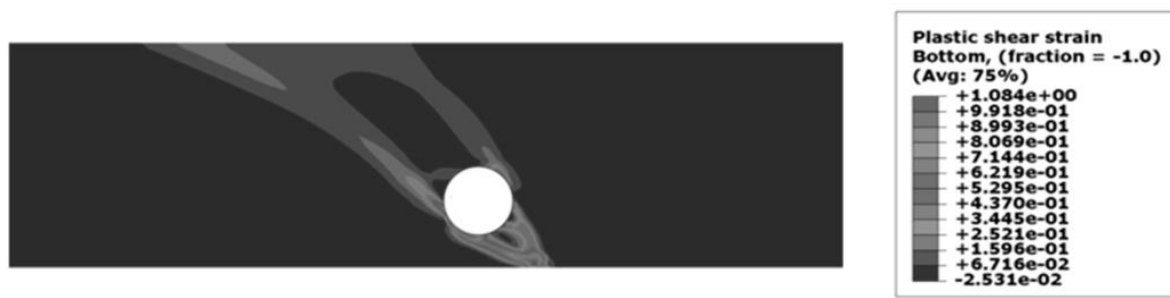

Fig. 6 The development of shear strain zone, obtained by the established numerical model.

\section{RESULTS}

This study focused on the effects of permanent fault displacement on response of tunnel lining. In fact, several specifications including sectional force distribution, displacement, and shear distortion of the lining section were evaluated, under two types of fault rupture with different earthquake magnitudes. To investigate the effect of the tunnel position relative to fault tip, tunnel was located in four different positions i.e. $F W 1 D, F W 3 D, F W 5 D$ and $H W 1 D(F W$ and $H W$ refer to the footwall and hanging wall, respectively. For example, $F W 3 D$ refers to the horizontal distance of three times of the tunnel diameter between the lining center and fault tip line in bedrock) (Figure 2).

\subsection{REVERSE FAULT}

\subsubsection{PLASTIC SHEAR STRAIN}

Reverse fault movement and its rupture in soil are mechanically analogous to a gravity wall under passive condition, with the exception that at steeper 


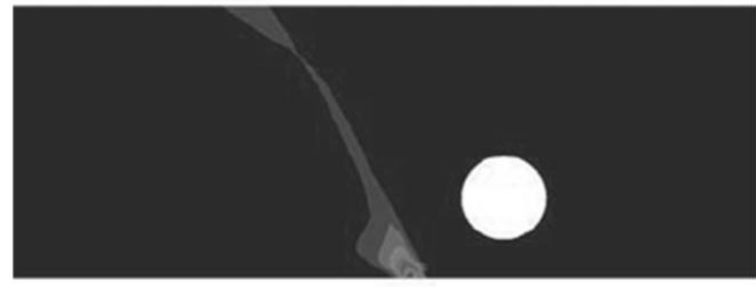

(a)
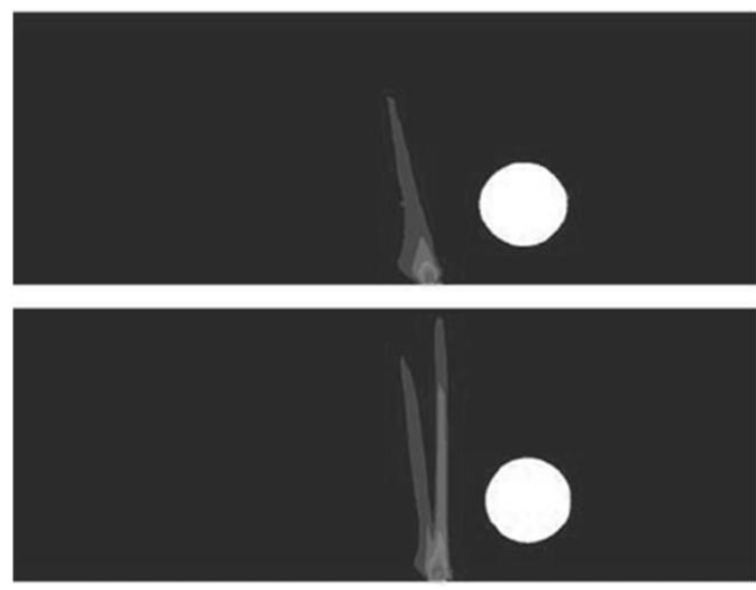

Fig. 6 The development of shear strain zone, obtained by the established numerical model.

fault dip angle (larger than $45^{\circ}$ ), its mechanism is similar to vertical uplifting in hanging wall side (Anastasopouos et al., 2008). Forming a passive wedge in hanging wall side makes a shearing failure zone and dominantly compression area in far at both hanging wall and footwall sides for free filed conditions. Due to reverse fault rupture propagation, the material inside the fault zone (passive wedge) reached the plastic state. By increasing the fault dip angle (from $45^{\circ}$ to $75^{\circ}$ ), the width of the shear zone (i.e. the width of passive wedge) decreased and the plastic shear zone have relocated farther than the footwall or closer to the hanging wall (Figure 6 and Figure 7). This is in agreement with theoretical results obtained by Anastasopoulos et al. (2008). Thus, by increasing the fault dip angle, the lining would get less influenced by the shear zone, if the tunnel was located in foot wall side. This event is opposite for the tunnel located on hanging wall side.

For cases in which the tunnel was located in shear path (the shear path in free field condition is prescribed by the closed form solutions), a bifurcation occurred, which is a change in fault rupture mechanism in soil. This event is based on the principal of minimum work. In fact, lining stiffness is higher than soil stiffness. That is why the plastic shear strain path is deviated to the invert and near to the vault of tunnel lining for FW1D case (Figure 8).

\subsubsection{SECTIONAL FORCES OF THE TUNNEL LINING}

For all fault dip angles, the maximum bending moment and axial load occurred in $F W 1 D$ and $H W 1 D$ cases, respectively. The shear zone passed

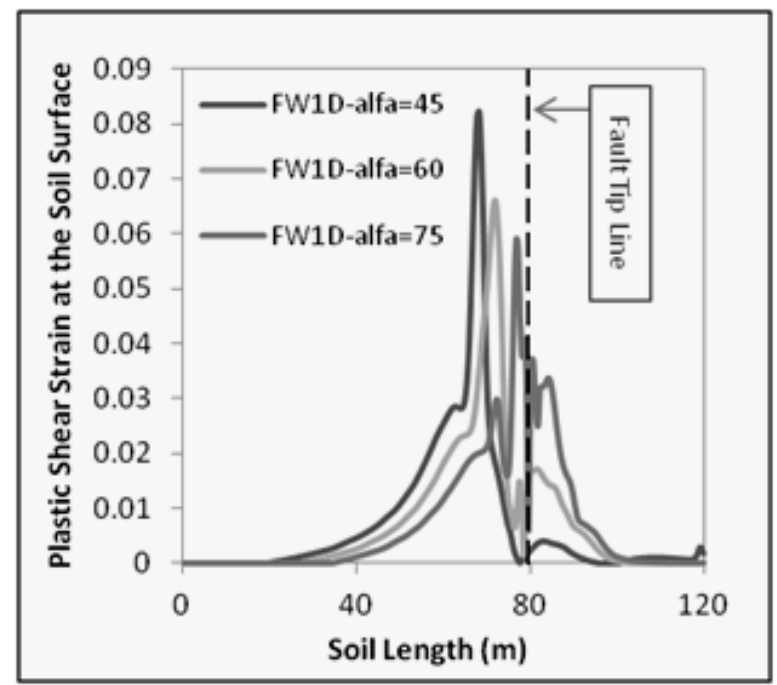

(c)

Fig. 7 Plastic shear strain due to reverse fault rupture in earthquakeswitha magnitude of 7 at HW1D with dip angles of (a) $45^{\circ}$, (b) $60^{\circ}$, and (c) $45^{\circ}$.

through $F W 1 D$ case and the plastic shear zone developed around the tunnel. Therefore, the maximum asymmetric loading and bending moment were applied on this case. In addition, the maximum bending moment gradient at different earthquake magnitudes for $F W I D$ case was greater than the one for farther cases. Furthermore, by moving upward and increasing field stresses in hanging wall, which tends to compress the tunnel, the maximum loading was applied on the lining for $H W I D$ case. This is the reason why the maximum axial load occurred for this case (Figure 9).

For all cases, the direction of the bending moment changed. Fault movement developed a shear zone in soil. Closer the tunnel positions were to the shear zone, more asymmetric loadingwas applied on them. For this reason, in each fault dip angles, the maximum bending moment and the change in its direction occurred at $F W 1 D$ case, firstly and then at $F W 3 D, H W 1 D$ and $F W 5 D$, respectively. For $H W 1 D$ case, by increasing fault dip angle, the maximum bending moment and change in its direction increased and decreased, respectively. In fact, the position of the maximum bending moment at $90^{\circ}$ of the lining section was transferred to the range of $200^{\circ}$ to $240^{\circ}$ (the apex of the tunnel is at right side of lining, thus, the tunnel vault is taken to be $90^{\circ}$ ). These events attribute to passive wedge deviated to hangingwall side by increasing fault dip angle. In this condition, the tunnel was closer to the shear rupture. Furthermore, steeper fault dip angle dominated vertical uplifting in hanging wall side. Thus, moving 

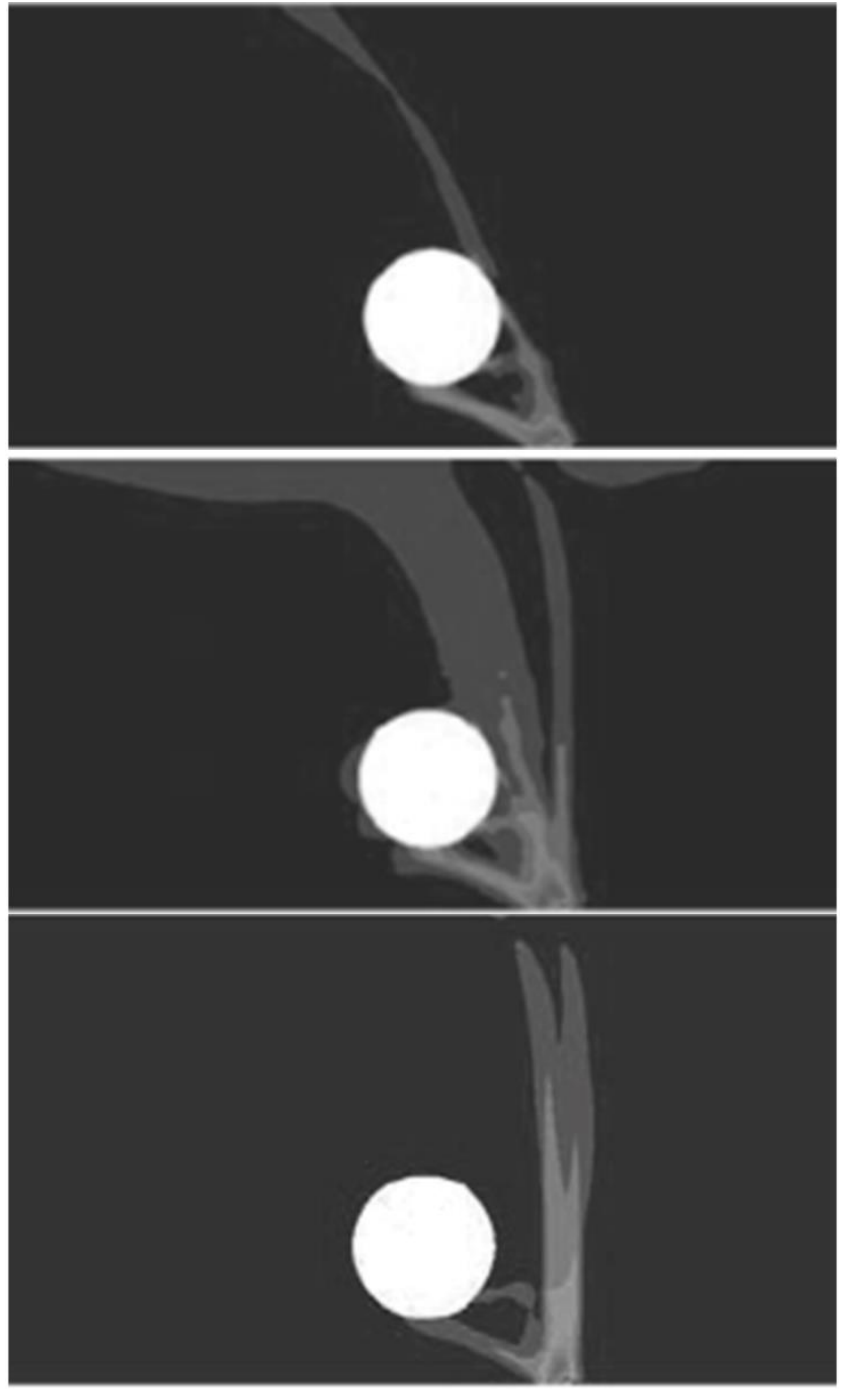

Fig. 8 The variations of plastic shear strain at the soil surface indicating the width of passive wedge and its deviation to the hanging wall side by increasing fault dip angle. upward and increasing stresses around the tunnel, the axial load increased throughout the lining section for $H W I D$ case. For $F W 1 D$ case, the direction of the bending moment changed and its distribution was rotatedabout $90^{\circ}$, independent of the fault dip angle. The position of the maximum bending momentat $90^{\circ}$ of the lining section was transferred to the range of $0^{0}-350^{\circ}$, passed by shear zone and the soil stress increased by established passive condition in this direction. In each fault dip angle, such a change in axial load was non-uniform. Also, for this case, by increasing fault dip angle, the maximum bending moment decreased. According to the distribution of the bending moment indicated for $F W 3 D, F W 5 D$ cases, farther the tunnel was located relative to fault rupture, more change in fault operation was around the tunnel lining; in other words, the changes in direction of principal stresses around the tunnels at FW1D and FW5D cases were different (Figure 10). Moreover, for these cases, the position of the maximum bending moment at $90^{\circ}$ of the tunnel lining sectionwas transferred to the range of $0^{\circ}-310^{\circ}$. Besides decreasing of the bending moment by increasing the fault dip angle, the same change in axial load could be observed. It is better to say that, by increasing fault dip angle, both sectional forces almost approached to primary condition before faulting for these cases. Variation of the bending moment for $F W 3 D$ case was more than that of $H W I D$ case, at fault dip angle of $45^{\circ}$ and it was the opposite for larger angles (i.e. at $75^{\circ}$ of the lining section). Totally, by increasing fault dip angle, the axial load decreased (Figs. 11-12).

\subsubsection{DISPLACEMENTS}

For $H W 1 D$ case, by increasing fault dip angle from $45^{\circ}$ to $75^{\circ}$, the horizontal and vertical displacements at the tunnel vault and the invert,
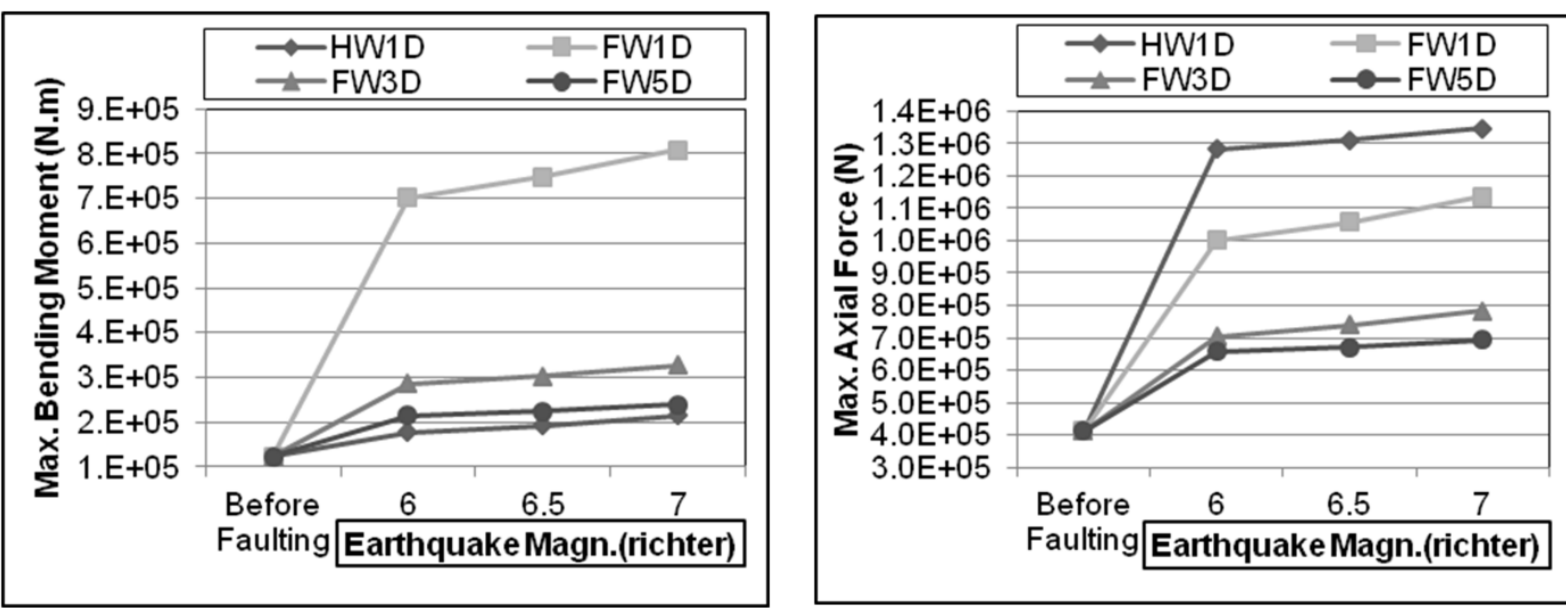

Fig. 9 The variations of plastic shear strain at the soil surface indicating the width of passive wedge and its deviation to the hanging wall side by increasing fault dip angle. 
Table 4 The displacements of the tunnel vault under reverse fault rupture $-\mathrm{cm}$.

\begin{tabular}{|c|c|c|c|c|c|c|c|c|c|}
\hline & \multirow{2}{*}{$M_{w}$} & \multicolumn{4}{|c|}{ Horizontal Displacement } & \multicolumn{4}{|c|}{ Vertical Displacement } \\
\hline & & $H W I D$ & $F W 1 D$ & $F W 3 D$ & $F W 5 D$ & $H W 1 D$ & $F W 1 D$ & $F W 3 D$ & $F W 5 D$ \\
\hline \multirow{2}{*}{$\simeq \stackrel{n}{\neg}$} & 6 & -30.8 & -23.1 & -10.6 & -5.70 & 39.5 & 17.9 & 2.04 & 0.201 \\
\hline & 7 & -38.2 & -27.5 & -12.7 & -6.66 & 48.8 & 21.1 & 2.84 & 0.316 \\
\hline \multirow{2}{*}{$\simeq 8$} & 6 & -22.7 & -18.1 & -7.66 & -4.32 & 46.6 & 14.4 & 1.13 & 0.060 \\
\hline & 7 & -27.3 & -20.7 & -8.89 & -4.92 & 56.6 & 16.4 & 1.47 & 0.107 \\
\hline \multirow{2}{*}{ 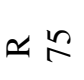 } & 6 & -11.9 & -12.7 & -5.21 & -3.10 & 51.3 & 10.3 & 0.61 & -0.028 \\
\hline & 7 & -14.1 & -14.7 & -5.99 & -3.50 & 62 & 12 & 0.737 & -0.011 \\
\hline
\end{tabular}

Table 5 Shear distortion of the tunnel cross-section under reverse faulting $-\mathrm{cm}$.

\begin{tabular}{|c|c|c|c|c|c|}
\hline & $M_{w}$ & $H W I D$ & $F W 1 D$ & $F W 3 D$ & $F W 5 D$ \\
\hline \multirow[t]{2}{*}{$\propto$ v } & 6 & 0.439 & -9.41 & -6.01 & -3.15 \\
\hline & 7 & 0.787 & -10.3 & -6.67 & -3.67 \\
\hline \multirow[t]{2}{*}{$\simeq 8$} & 6 & -0.3 & -9.17 & -4.76 & -2.38 \\
\hline & 7 & -0.1 & -10.1 & -5.47 & -2.72 \\
\hline \multirow[t]{2}{*}{$\simeq$ : } & 6 & -1.14 & -6.53 & -3.31 & -1.7 \\
\hline & 7 & -1.0 & -7.87 & -3.8 & -1.9 \\
\hline
\end{tabular}

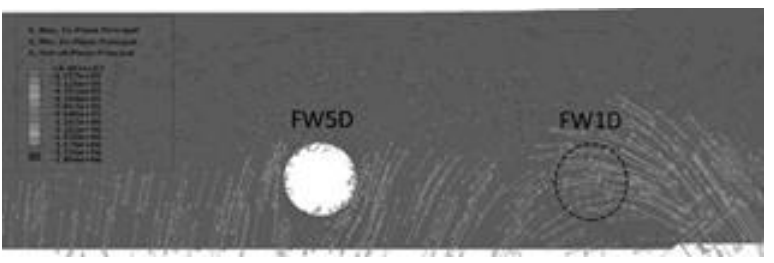

Fig. 10 The direction of principal soil stresses around the tunnel at FW1D and FW5D after earthquake fault rupture with magnitude 7 and dip angle of $45^{\circ}$. decreased and increased, respectively. This event is due to the fact that the horizontal and vertical components of fault movement decreased and increased, respectively, on the one hand, and the width of induced passive wedge decreased by increasing fault dip angle, on the other. That is why the required horizontal movement decreased to reach the failure state. In addition, for $H W 1 D$ case, at a constant fault dip angle, the horizontal and vertical displacements at the tunnel vault and the invert were the same. It shows that no shear distortion occurred at the tunnel cross section. For $F W 1 D$ case, by increasing the fault dip angle in different earthquake magnitudes, both components of displacement at the tunnel vault and the invert decreased, while the displacements at the tunnel vault were approximately double in size comparing the one at the invert. Therefore, shear distortion and rotation occurred for the tunnel crosssection. For $F W 3 D$ and $F W 5 D$ cases, by moving farther away from the fault tip, at a constant dip angle (particularly, large angles), the displacements at the tunnel vault and the invert were constant. In other word, the displacements were independent of the amount of fault slip. In these cases, no vertical displacements occurred at the tunnel vault and the invert, compared to the horizontal ones. This result indicates that the tunnels were located far away from the fault line in footwall side (i.e. greater than $3 D$ ), only the horizontal component of reverse fault dislocation was influential. Therefore, by increasing the fault dip angle and decreasing the horizontal fault dislocation, the horizontal displacement of the tunnel decreased (see Table 4).
As indicated in Table 5, the maximum shear distortion occurred at $F W 1 D$ case. The lining shear distortion for $F W 1 D$ case did not increase by increasing fault displacement, except for fault dip angle $75^{\circ}$ (i.e. by increasing earthquake magnitude from Ms6 to Ms7) and instead, the tunnel lining moved more vertically and horizontally as a rigid body rather than having structural distortion. This is well justified by the fault rupture bifurcation and the associated diffusion of plastic shear strain to the tunnel vault and invert. Also, the same behavior was concluded for other cases at each fault dip angle, however, because of a different reason. In fact, other cases, all were out of passive wedge induced by reverse faulting, and as a result, uniform displacements with small distortion occurred at tunnel lining.

For more accurate assessment, the stress field around the tunnel was evaluated. For $F W I D$ case, due to fault movement, in some areas around the tunnel, the soil moved toward the tunnel lining or far away from that, thus, a compression with increasing contact stress on the lining and a detachment between the lining and soil with stress relief occurred, respectively. In this case, for each fault dip angle in different earthquake magnitudes, the soil stress on the tunnel lining reached the failure state, such that, two passive zones and two active zones occurred at tunnel perimeter, due to the increase and decrease of contact stress, respectively. The research carried out by Lin et al. (2007), with regard to the impact of thrust faulting on underground tunnels discussed a similar phenomenon. The details of deformation pattern and 


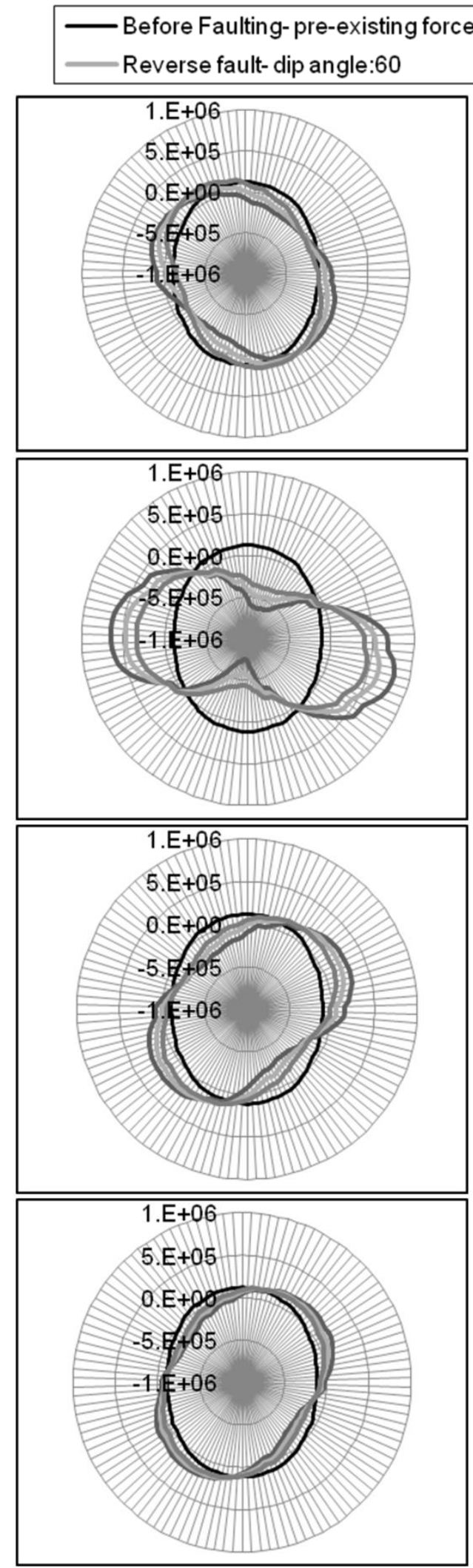

Fig. 11 Bending moment distribution at reverse fault with dip angles of $45^{\circ}, 60^{\circ}$, and $75^{\circ}$ for (a) HW1D, (b) FW1D, (c) FW3D, (d) FW5D cases.
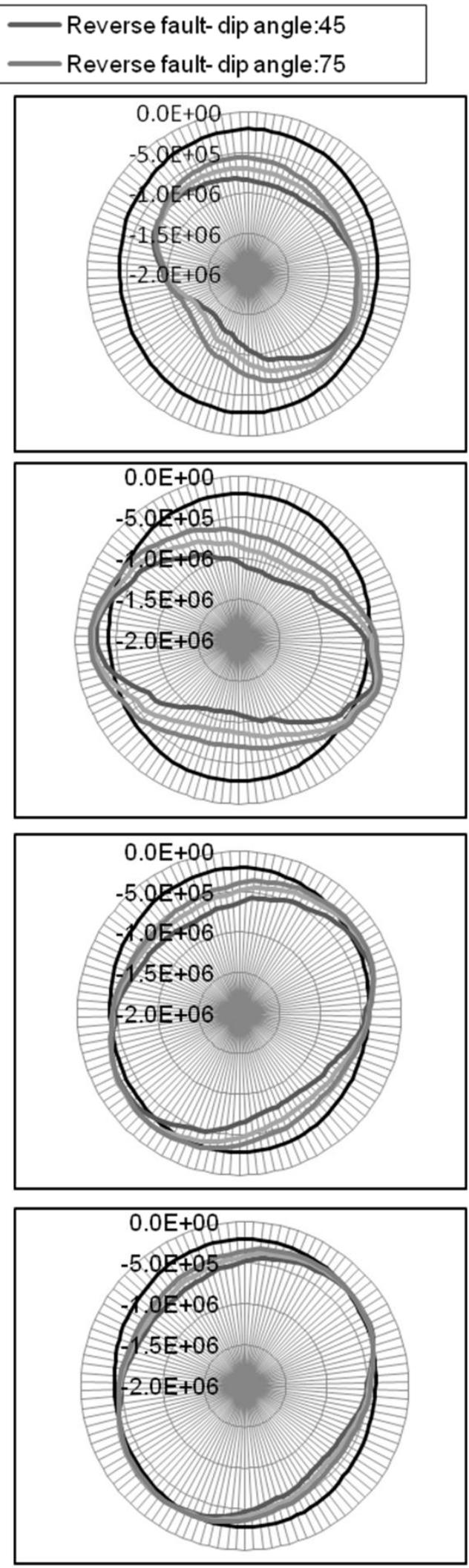

Fig. 12 Axial load distribution at reverse fault with dip angles of $45^{\circ}, 60^{\circ}$, and $75^{\circ}$ for (a) HW1D, (b) FW1D, (c) FW3D, (d) FW5D cases. 


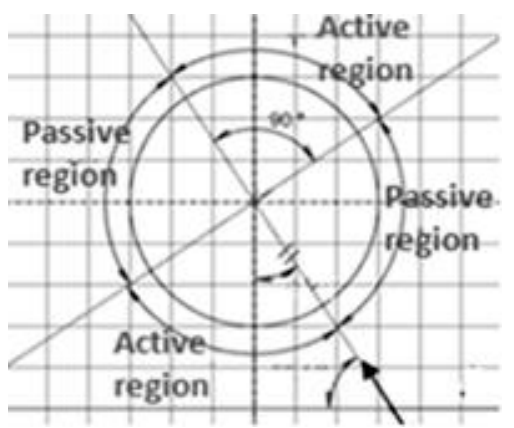

Fig. 13 The surrounding earth pressure on the tunnel lining, induced by reverse fault movement.
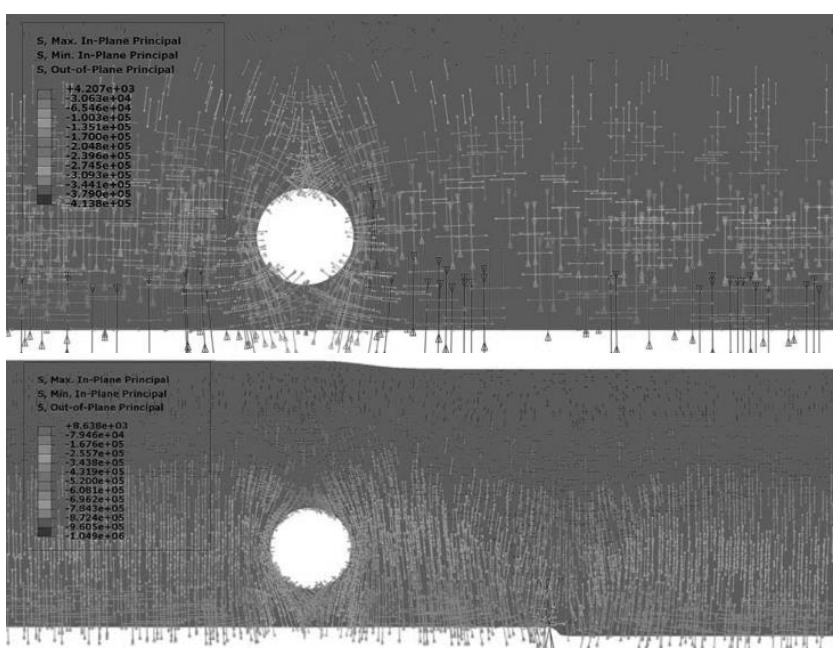

Fig. 15 The direction of principal stresses around the tunnel for FW3D case (a) before faulting, (b) after normal fault rupture with magnitude of 7 and dip angle of $45^{\circ}$.

the pressure state around the tunnel were obtained (see Figure 13). In addition, evaluating of contact stresses for other cases revealed that there is no failure state around the tunnel at each fault dip angle.

\subsection{NORMAL FAULT}

\subsubsection{PLASTIC SHEAR STRAIN}

Normal fault movement and its rupture in soil are mechanically analogous to a gravity wall under active condition. There is an especial condition in this fault type. In fact, at fault dip angle lower than $45^{\circ}+\psi / 2$, a gravity graben would be formed by developing a secondary fault rupture on the hanging wall side. This condition makes a superimposed vertical displacement (Anastasopouos et al., 2008). Forming an active wedge, width of the influenced zone under normal fault rupture was less than the one under reverse fault. This is compared well with theoretical results obtained by Anastasopoulos et al. (2008). For this reason, the tunnel was less influenced by normal faulting. In fact, the plastic shear strain passed near by the tunnel without any bifurcation of the shear path (Figure 14).

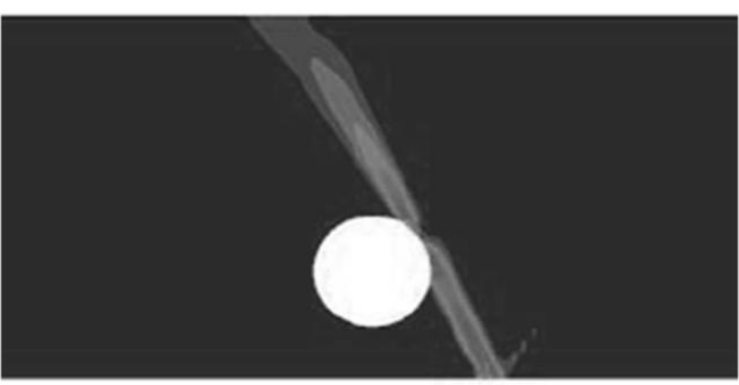

(a)

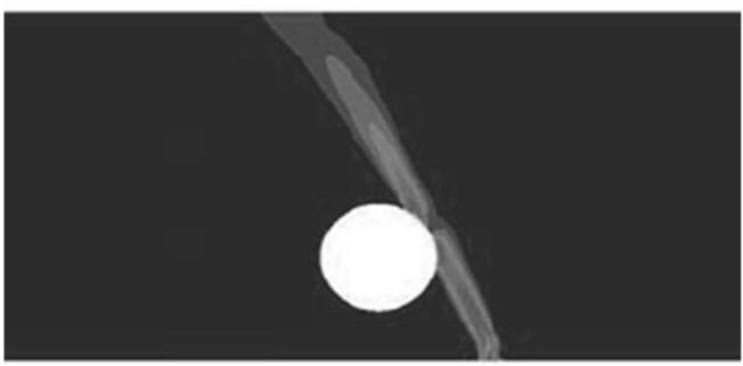

(b)

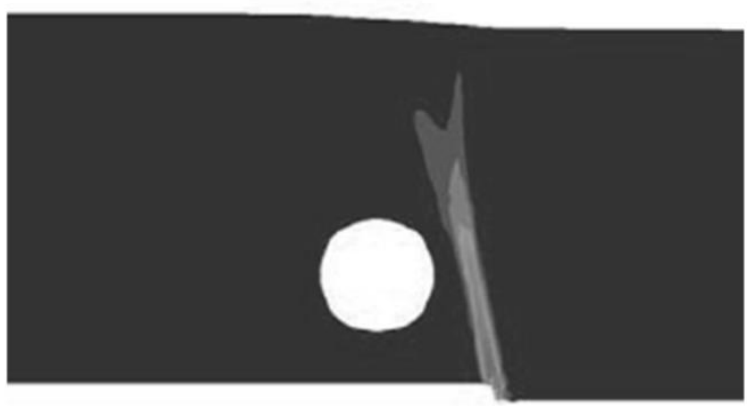

(c)

Fig. 14 Maximum plastic shear strain,induced by normal faulting in earthquakeswith magnitude of 7 for FW1D with fault dip angles of (a) $45^{\circ}$, (b) $60^{\circ}$, (c) $75^{\circ}$.

In addition, the quantity of plastic shear strain induced by normal fault was greater than that of the reverse fault. Due to the fact that the reverse fault mechanism is thrusting; the soil shear strength under reverse fault is more than the one under normal fault (Figure 14).

\subsubsection{SECTIONAL FORCES OF THE TUNNEL LINING}

For $F W 1 D$ case, the maximum axial load and bending moment were applied on the tunnel lining, for all fault dip angles and in different earthquake magnitudes. This is due to the established active condition in footwall and the increased downward stresses at this side and also as a result of shearing. Moreover, the most changes in the maximum axial load and the bending moment occurred at this case. In contrast to reverse fault rupture, there was no change in direction of the bending moment, due to the fact that the direction of stress field around the tunnel was constant. In fact, just because of increasing and decreasing pressure on soil-tunnel lining interface (i.e. contact stresses), the positive and negative bending moment increased (Figure 15). For this case, the axial 

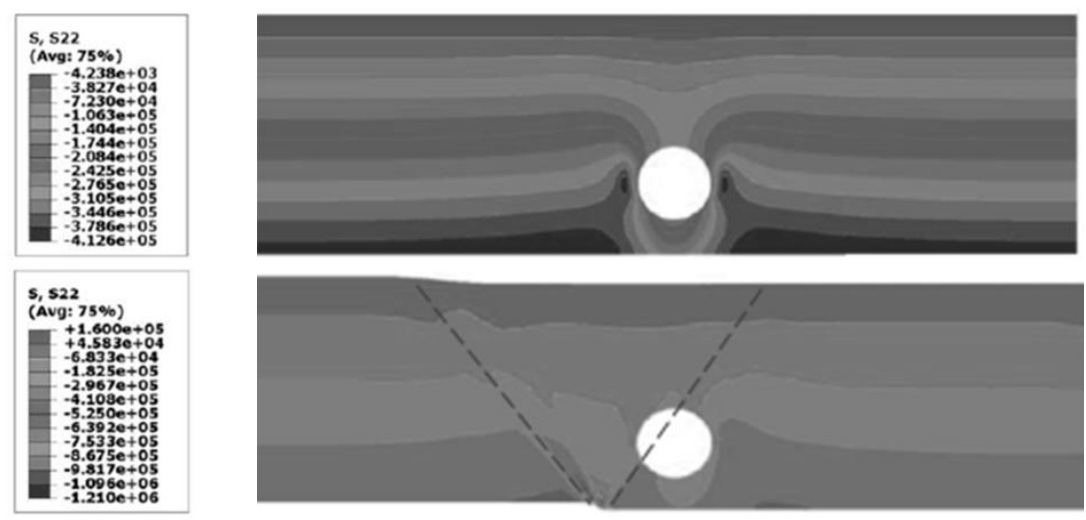

Fig. 16 The contours of vertical stress for HW1D case (a) before faulting, (b) after normal fault rupture with earthquake magnitude of 7 and dip angle of $45^{\circ}$; indicative of forming gravity graben.

Table 6 The displacements of the tunnel vault under normal fault rupture-cm.

\begin{tabular}{|c|c|c|c|c|c|c|c|c|c|}
\hline & \multirow{2}{*}{$M_{w}$} & \multicolumn{4}{|c|}{ Horizontal Displacement } & \multicolumn{4}{|c|}{ Vertical Displacement } \\
\hline & & $H W 1 D$ & $F W I D$ & $F W 3 D$ & $F W 5 D$ & $H W I D$ & $F W 1 D$ & $F W 3 D$ & $F W 5 D$ \\
\hline \multirow{2}{*}{ z キ } & 6 & 13.7 & 3.69 & 0.951 & 0.6 & -16.1 & -3.17 & -0.34 & -0.062 \\
\hline & 7 & 61.7 & 4.25 & 1.11 & 0.6 & -67.1 & -3.92 & -0.431 & -0.096 \\
\hline \multirow{2}{*}{$z 8$} & 6 & 10.7 & 2.80 & 0.729 & 0.333 & -18.3 & -3.06 & -0.229 & -0.003 \\
\hline & 7 & 45.6 & 2.60 & 0.554 & 0.143 & -78.8 & -3.62 & -0.224 & 0.025 \\
\hline \multirow{2}{*}{$z \stackrel{n}{n}$} & 6 & 7.10 & 1.92 & 0.46 & 0.3 & -19.3 & -3.15 & -0.106 & -0.003 \\
\hline & 7 & 26.5 & 0.696 & -0.017 & 0.1 & -85.8 & -3.66 & 0.064 & 0.025 \\
\hline
\end{tabular}

load increased for all fault dip angles and the maximum was at $75^{\circ}$ of the lining section, owning to the fact that by increasing fault dip angle; close to vertical downward movement, the associated contact stresses on the tunnel increased. For $H W 1 D$ case, the bending moment and axial load increased considerably, at fault dip angle of $45^{\circ}$. This event is attributed to the developed secondary shearing and forming a gravity graben on hanging wall side (Figure 16). In fact, forming graben increases vertical displacement and contact stress on the lining and also, shearing increases the bending moment; instead, by increasing fault dip angle and then decreasing contact stresses around the tunnel due to tensional stresses and stress relief around the lining on hanging wall side, the axial load and the bending moment decreased. For $F W 3 D$ case, the changes in earthquake magnitudes at each fault dip angle had no effect on the maximum axial load. In addition, fault rupturing caused to increase positive bending moment with no change in its direction, while, further increase of the fault dip angle led the bending moment to primary measures. For $F W 5 D$ case, for all fault dip angles in different earthquake magnitudes, the sectional force had no change. Overall, by increasing distance to the fault tip (i.e. more than $5 D$ ), the sectional forces were constant, due to the fact that the influenced shear zone was far enough to affect the tunnel (Figs. 17-20).

\subsubsection{DISPLACEMENTS}

For $F W 3 D$ and $F W 5 D$ cases, by increasing fault dip angle indifferent earthquake magnitudes, there was almost no displacement at the tunnel vault and the invert. At a constant fault dip angle, by increasing the earthquake magnitude, the horizontal and vertical displacement at the tunnel vault were constant and lower than $1 \mathrm{~cm}$; instead, no displacement occurred at the tunnel invert (i.e. lower than $5 \mathrm{~mm}$ ). This result implies that under normal faulting, the displacements of the tunnel lining section, located in footwall, were independent of both the earthquake magnitudes and the fault dip angles. For all fault dip angles in different earthquake magnitudes, the maximum displacement at the tunnel vault and invert occurred at $H W 1 D$ case. In fact, for $H W 1 D$ case, the variations of the displacements of the tunnel were high due to a wide difference between permanent fault dislocations, induced by normal faulting in different earthquake magnitudes. Also for this case, by increase of the fault dip angle, the horizontal and the vertical displacement decreased and increased, respectively. By increasing the earthquake magnitude from 6 to 7 , the shear distortion of the lining increased. This shows that further increase of fault dislocation leads to accumulation of additional strain in primary shear path which superimposes the lining distortion. Moreover, in each fault dip angle in different 


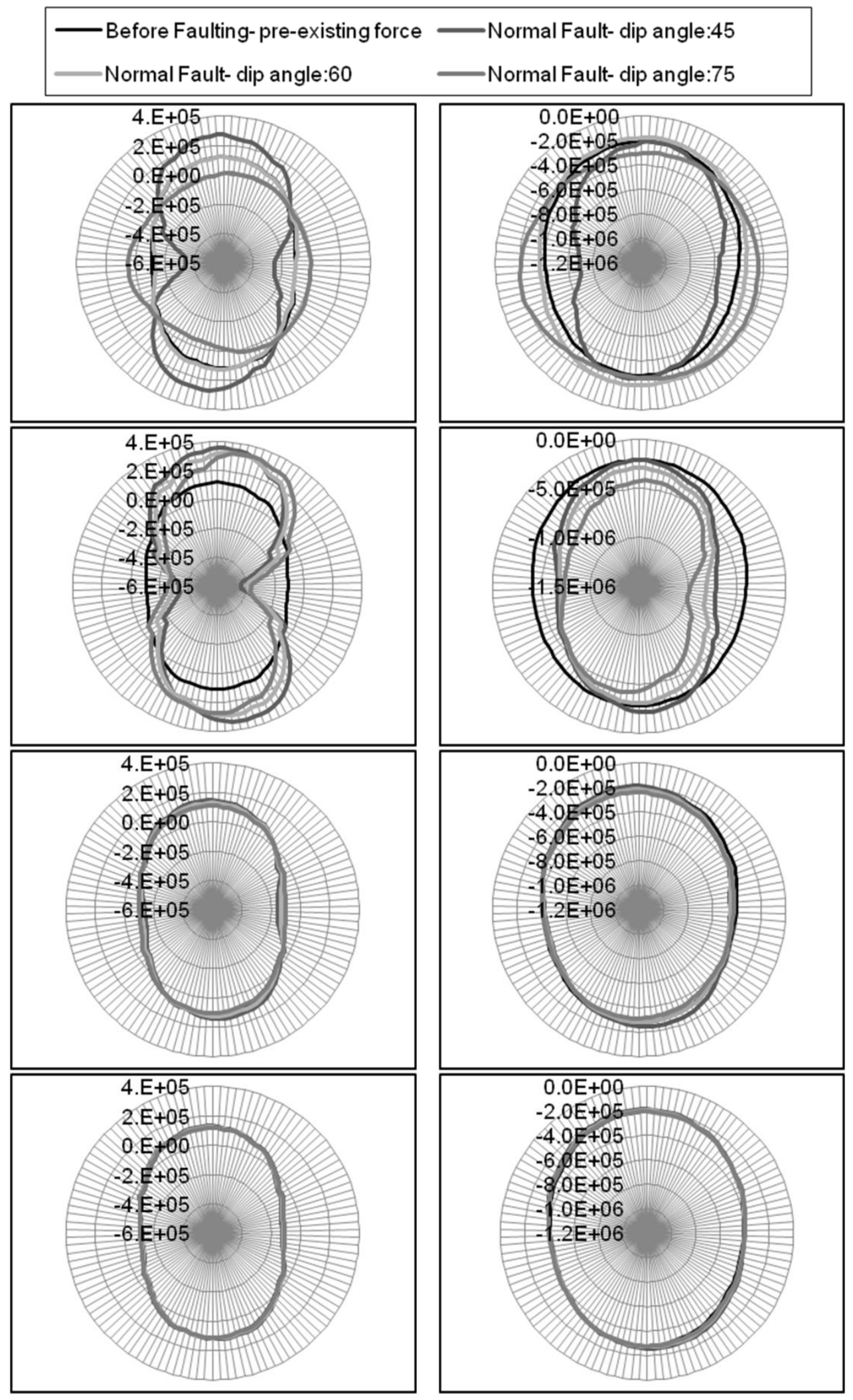

Fig. 19 The bending moment distribution under normal fault rupture with dip angles of $45^{\circ}, 60^{\circ}$, and $75^{\circ}$ for (a) HW1D, (b) FW1D, (c) FW3D, (d) FW5D cases.

Fig. 20 The axial load distribution under normal fault rupture with dip angles of $45^{\circ}, 60^{\circ}$, and $75^{\circ}$ for (a) HW1D, (b) FW1D, (c) FW3D, (d) FW5D cases. 
earthquake magnitudes, the displacements at the tunnel vault and the invert were approximately the same. For $F W 1 D$ case, the displacements at the tunnel vault were lower than $4 \mathrm{~cm}$; instead, they were lower than $1 \mathrm{~cm}$ at the invert. In fact, further increase of the fault dislocation caused a rigid- body movement (see Table 6). Nevertheless, $F W 1 D$ and $H W 1 D$ cases had greater shear distortion than the other ones, as presented in Table 7.

Again for more accurate assessment, the stress field around the tunnel was evaluated for these cases. As mentioned previously, due to fault movement, in some areas around the tunnel, the soil moved toward the tunnel lining or far away from that; thus, the contact stresses on the tunnel lining increased and decreased, respectively. Also, under the normal fault rupture, the structure is subjected to high contact pressure in one direction which tends to compress the lining and a stress relief in the orthogonal direction with detachment between soil and the lining, simultaneously. Here, only the reduction in earth pressures approached the active failure state, exclusively under fault dip angle $45^{\circ}$. This was slightly different from the one which occurred for the tunnel under reverse fault rupture. Furthermore, details of the deformation pattern around the tunnel and an idealized zone were brought in Figure 21.

\section{CONCLUSION}

This study focused on evaluating the tunnel behavior by means of sectional forces, displacement, and searching for safe distance between the tunnel and fault tip. In order to reach these goals, a finite elements based on 2D model was adopted. Considering different aspects of tunnel position relative to active faults and other types of fault (strike slipping), more accurate studies should be performed based on 3D models. According to the soil properties (loose sand) and the specific tunnel lining structure considered in this study, the results are as follows

1. The magnitude of the bending moment corresponding to the tunnels located in footwall, for all reverse fault dip angles, is greater than the one in the normal faults, whereas the bending moment corresponding to the tunnels located on hanging wall at the normal fault dip angles (i.e.

Table 7 Shear distortion of the tunnel cross-section under normal faulting $-\mathrm{cm}$.

\begin{tabular}{llllll} 
& $M_{w}$ & $H W 1 D$ & $F W 1 D$ & $F W 3 D$ & $F W 5 D$ \\
\hline 乙 & 6 & -0.6 & 2.66 & 0.507 & 0.3 \\
& 7 & -1.8 & 2.84 & 0.578 & 0.3 \\
乙 & 6 & 0.5 & 2.4 & 0.445 & 0.175 \\
& 7 & 0.7 & 2.37 & 0.391 & 0.0774 \\
乙 & 6 & 1.43 & 2.21 & 0.37 & 0.1 \\
& 7 & 2.38 & 1.8 & 0.162 & 0.0341 \\
\hline
\end{tabular}

lower than $45^{\circ}$ ) is greater than the one in the reverse fault and it is the opposite for fault dip angles larger than $45^{\circ}$.

2. The magnitude of the axial load corresponding to the tunnels located near the fault in footwall, under reverse fault dip angles lower than, is greater than the one in normal fault and it is the opposite for angles larger than $60^{\circ}$. For the tunnels located in a distance more than $3 D$ relative to the reverse fault tip in footwall, the axial load is greater than the one in normal fault. In addition, for the tunnels located in hanging wall, for all reverse fault dip angles, the axial load is greater than the one in normal faults.

3. The horizontal and vertical displacements of the tunnel, located in hanging wall in earthquakes with magnitudes of more than 7 at any normal fault dip angle, are greater than those in reverse fault. This is opposite for the earthquake magnitudes of lower than 7; whereas for the tunnels located in footwall, in each reverse fault dip angle, it is greater than the one in normal fault.

4. The shear distortion (the horizontal displacement of the tunnel vault relative to the invert) of the tunnel cross-section, located in hanging wall and induced by normal faulting. It is 1.5 to 7 times more than the one induced by reverse faulting, whereas for the tunnels located in footwall, it is about 3 times.

5. The recommended safe distance for the tunnels located in footwall, under reverse fault displacement and in earthquake magnitudes of greater than 6 , is at least more than $3 D$ to $5 D$ and for the tunnels located in hanging wall is at least more than $2 D$ to $3 D$.

6. The recommended safe distance for the tunnels located in footwall, for all normal fault displacements in earthquake magnitudes of greater than 6 , is at least 3 times the tunnel lining's diameter, and such a safe distance, for those located in hanging wall is at least more than $2 D$.

\section{REFERENCES}

Anastasopoulos, I., Gerolymos, N., Gazetas, G. and Bransby, M.F.: 2008, Simplified approach for design of raft foundations against fault rupture. Part I: freefield. Earthquake Engineering and Engineering Vibration, 7, 147-163.

DOI: $10.1007 / \mathrm{s} 11803-008-0835-6$

Anastasopoulos, I. and Gazetas, G.: 2010, Analysis of cutand-cover tunnels against large tectonic deformation. Bull Earthquake Eng, 8, 283-307. DOI 10.1007/s10518-009-9135-4

Bray, J.D.: 1990, The effects of tectonic movements on stresses and deformations in earth embankments. Ph.D. Dissertation, University of California, Berkeley.

Bray, J.D., Seed, R.B., Cluff, L.S. and Seed, H.B.:1994, Earthquake fault rupture propagation through soil. J. 


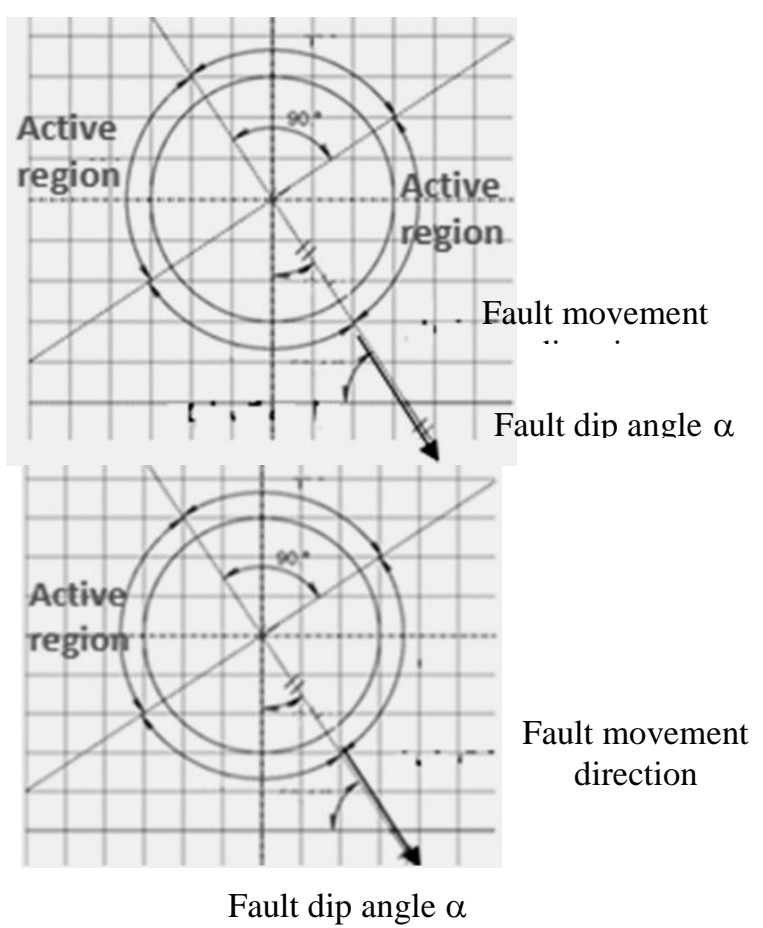

Fig. 21 The surrounding earth pressure on the tunnel lining for (a) FW1D, and (b) HW1D cases, induced by normal fault movement with dip angle of. $45^{\circ}$.

Geotech. Eng, 120, No. 3, 543-561. DOI: 10.1061/(ASCE)0733-9410(1994)120:3(543)

Chung, C.F., Lin, M.L., Jeng, F.S., Tsai, L.S., Chin, C.T. and Chan, S.J.: 2005, A case study on the response of shield tunnel near a thrust fault offset. Proceedings of Geotechnical Earthquake Engineering, Satellite Conference, Osaka, Japan.

Corigliano, M.: 2007, Seismic response of deep tunnels in near-fault conditions. Ph.D. dissetation, Politecnico di Torino.

Dowding, C.H. and Rozen, A.: 1978, Damage to rock tunnels from earthquake shaking. Journal of the Geotechnical Engineering Division, ASCE, 104, GT2, 175-191.

Einstein, H.H. and Schwartz, C.W.: 1979, Simplified analysis for tunnel supports. Journal of the Geotechnical Engineering Division, ASCE, 105, GT4, 499-518.

I.T.A.Working Group on general approaches to the design of tunnels.: 2000, Guidelines for the design of the shield tunnel lining.Tunnelling and Underground Space Technology, 15, No. 3, 303-331.

Jaky, J.: 1944, The coefficient of Earth pressure at rest. Journal for Society of Hungarian Architects and Engineers, 8, No. 22, 355-358.

Lee, K.M., Hou, X.Y., Ge1, X.W. and Tang, Y.: 2001, An analytical solution for a jointed shield-driven tunnel lining. Journal of Numerical and Analytical Methods in Geomechanics , 25, No. 4, 365-390.
Lin, M.L., Chung, C.F., Jeng, F.S. and Yao, T.C.: 2007, The Deformation of overburden soil induced by thrust faulting and its impact on underground tunnels. Engineering Geology, 92, 110-132.

DOI: $10.1016 /$ j.enggeo.2007.03.008

Muir Wood, A.M.: 1975, The circular tunnel in elastic ground. Geotechnique, 25, No. 1, 115-127. DOI: 10.1680/geot.1975.25.1.115

Power, M.S., Rosidi, D. and Kaneshiro, J.Y.: 1998, Seismic vulnerability of tunnels and underground structures revisited. Proc. North American Tunnelling Conference '98. Newport Beach, CA. Balkema, Rotterdam, the Netherlands, 243-250.

Wells, D. and Coppersmith, K.: 1994, New empirical relationships among magnitude, rupture length, rupture width, rupture area, and surface displacement. Bulletin of the Seismological Society of America, 84, No. 4, 974-1002. 